\title{
Rapid Quantification of Gene Expression by Competitive RT-PCR and Ion-Pair Reversed- Phase HPLC
}

BioTechniques 20:250-257 (February 1996)

\author{
Amanda Hayward-Lester, \\ Peter J. Oefner ${ }^{1}$ and Peter \\ A. Doris \\ Texas Tech University Health \\ Sciences Center, Lubbock, TX, \\ and ${ }^{1}$ Stanford University, \\ Stanford, CA, USA
}

\begin{abstract}
Competitive reverse-transcription $P C R$ (RT-PCR) techniques for quantification of gene expression employ titrations in which the products of multiple PCRs must be separated, analyzed and quantified to compute gene expression in a single sample. We have employed a novel, ion-pair reversed-phase HPLC (IP-RP-HPLC) system to analyze and quantify RT-PCRs performed with mutant RNA internal standards. PCR products could be separated and quantified in $6 \mathrm{~min}$ utes per reaction using the absorbance signal from an on-line UV detector. Crude $P C R$ products can be analyzed without further processing and without the addition of radioactive or fluorescent markers to reactions. Analysis of titration regression and slope values approached mathematical ideals indicating that amplification of native and competitor RNA occurred with equal efficiency. Further, serial dilution of input RNA over three orders of magnitude did not affect the calculated level of gene expression or the slope of the titration. IP$R P$-HPLC appears to offer important advantages to quantitative measurements of gene expression. These include rapid sample analysis and column re-equilibration, reduced sample handling and opportunity for introduction of quantification error, avoidance of fluorescent or radioactive tracers, high detector sensitivity and linearity and excellent quantitative reliability.
\end{abstract}

\section{INTRODUCTION}

The polymerase chain reaction (PCR), in conjunction with reverse transcriptase, has provided a convenient and highly sensitive method for examining gene expression. In many settings, accurate quantitative information concerning the level of gene expression is desirable $(7,15,22)$. Modifications of the reverse-transcription PCR (RT-PCR) method to accomplish this goal have been introduced. BeckerAndré and Hahlbrock were the first to propose the use of competition assays employing a competitor mutant RNA of the gene of interest (1). In this system, the RNA homolog shares the same sequence that is recognized by the reaction primers but is modified either to alter the existence of a restriction site or to alter the length of the sequence intervening between the primer binding sites. Mutant internal standard RNA is added in a range of known quantities to multiple reactions each containing uniform amounts of the RNA preparation to be quantified. Gene expression is estimated by observing the relative amount of native and homolog products resulting from RT-PCR. Numerous applications of this approach in varying modifications have now been published $(6,23)$.

As this technique gains wider application, there is a growing need to develop methods which provide accurate quantitative analysis of competitive RTPCRs but which limit the labor-intensive analysis of the products of multiple titration assays. Current methods employed to quantify the products of competitive RT-PCRs center on gel electrophoresis, though some exceptions exist (12). After separation of the reac- tion products, quantification is based on the use of radiolabeled or fluorescent PCR components. Reaction products have been measured by excising the bands and counting the radioactivity contained in them (15) or performing phosphor imager analysis of the resolved products (5). Some groups have hybridized labeled DNA probes to blots made from gels resolving PCR products (1), while others have employed fluorescent primers in the PCR and measured fluorescence of the resulting bands (14). Each of these approaches suffers the disadvantage that two steps are necessary to measure the reaction products. Each can be time-consuming and each introduces the possibility of errors that may impair accuracy. The ideal approach would reduce post-reaction analysis to a single step, eliminate the time-consuming activities of gel preparation, loading, running and analysis, eliminate the need to use radioactive components, lend itself to convenient automation and produce accurate and reproducible measurements of gene expression.

Several reports have appeared describing the application of HPLC to the analysis of PCR products. These reports have employed nonporous resin-based, anion-exchange column packings that have been adapted for rapid analysis but require re-equilibration intervals between runs $(3,4,13$, 24). Recently, IP-RP-HPLC on alkylated nonporous poly(styrene-divinylbenzene) particles has been shown to be well suited to rapid, automated quantitative analysis of double-stranded DNA (dsDNA) fragments in the pico- to femtomole range by on-line UV absorbance (9) or fluorescence (16) detection, respectively, with calibration curves ex- 
hibiting linearity over three orders of magnitude. Building on these features, as well as on the size-dependence of elution (10), the applicability of IP-RPHPLC to the quantitation of competitive RT-PCR products is demonstrated.

\section{MATERIALS AND METHODS}

\section{Production of Competitive Mutant RNA}

Rat sodium, potassium-ATPase alpha 1 isoform (NKA $\alpha 1)$ cDNA was generously provided by Dr. Jerry Lingrel (University of Cincinnati). The partial cDNA was provided in a pUC18 construct. It was removed from this construct by digestion with EcoRI and HindIII. The NKA $\alpha 1$ partial cDNA was isolated by agarose gel electrophoresis of the restriction digest products, cut from the agarose gel and ligated into the multiple cloning site of pGEM $^{\circledR}{ }^{\circledR} 4 \mathrm{Z}$ (Promega, Madison, WI, USA).

Rat angiotensinogen cDNA (a gift of Dr. Kevin Lynch, University of Virginia) was digested with $P p u \mathrm{M} 1$, the resulting fragments were separated by agarose slab gel electrophoresis and the 145-bp fragment was excised. The pGEM-4Z construct was digested with $P p u \mathrm{M} 1$, and the 145-bp angiotensinogen cDNA fragment was ligated to produce a construct in which the NKA $\alpha 1$ cDNA was interrupted by the presence of $145 \mathrm{bp}$ of angiotensinogen cDNA. Synthetic RNA (541 bases) was synthesized from the T7 polymerase promoter (T7 kit; Novagen, Madison, WI, USA) contained in this construct after digestion with EcoRI. Synthetic sense RNA was recovered by isopropanol precipitation at room temperature, washed and then quantified by spectrophotometry. The recovered RNA was checked for purity and quality on a denaturing agarose (MetaPhor ${ }^{\circledR}$; FMC BioProducts, Rockland, ME, USA) gel and stored at $-70^{\circ} \mathrm{C}$ in diethylpyrocarbonate (DEPC)-treated water.

\section{Primer Design}

We employed the Primer 0.5 program generously provided by the Lander laboratory, Whitehead Institute for Biomedical Research, MIT, to design primers for PCR amplification. The primers selected were designed to avoid dimerization and to span an intron so as to distinguish amplification of cDNA from any genomic DNA that may have contaminated samples. The forward primer sequence was an 18-mer:

5'-CCCTAGTTCCCGCCTCTC, the reverse primer was a 21-mer: 5'-TGGTCGTCCATAGACACTTCC. These primers yield PCR products of
245 bp (native) and 390 bp (insertion mutant). Primers were synthesized by the Texas Tech University Biotechnology Core Facility and were checked for homogeneity by HPLC.

\section{RNA Preparation}

Total RNA was prepared from whole rat blood by the addition of 
100-200 $\mu \mathrm{L}$ of blood to $800 \mu \mathrm{L}$ RNAzol $^{\mathrm{TM}}$ B (Biotecx Laboratories, Houston, TX, USA; currently available from Tel-Test, Friendswood, TX, USA). After extraction by the manufacturer's recommended procedure, the integrity of the RNA was checked by denaturing gel electrophoresis, dissolved in DEPC-treated water and quantitated by spectrophotometry; the remaining RNA was stored frozen at $-70^{\circ} \mathrm{C}$.

\section{PCR Conditions}

Competitor mutant RNA was diluted in a solution of $20 \mu \mathrm{g} / \mathrm{mL}$ yeast total RNA from a working stock solution of competitor RNA (100 ng/ $\mu \mathrm{L})$. Yeast total RNA was added as carrier to reduce nonspecific binding of mutant RNA to the dilution tubes. The range of dilutions of competitor that were added to the reverse transcription reactions was $1,5,10,20,50$ and $100 \mathrm{fg} / \mu \mathrm{L}$. One microliter of these dilutions was added to approximately $0.1 \mu \mathrm{g}$ of blood total RNA. The mixture was reverse-transcribed in a $10-\mu \mathrm{L}$ reaction volume using Moloney murine leukemia virus (MMLV) reverse transcriptase and random hexamer primers (Perkin-Elmer, Norwalk, CT, USA) The RT reaction was performed at $42^{\circ} \mathrm{C}$ for $25 \mathrm{~min}$, followed by $5 \mathrm{~min}$ at $99^{\circ} \mathrm{C}$ and then cooled rapidly to $5^{\circ} \mathrm{C}$. The $\mathrm{RT}$ reaction was overlaid with Chill-out 14 wax $^{\mathrm{TM}}$ (MJ Research, Watertown, MA, USA), and incubations were performed in 200 $\mu \mathrm{L}$ tubes in a Peltier-effect Thermal Cycler (MiniCycler ${ }^{\mathrm{TM}}$; MJ Research).

PCRs were initiated by the addition of $40 \mu \mathrm{L}$ of PCR master mixture containing AmpliTaq ${ }^{\circledR}$ DNA polymerase (Perkin-Elmer) at a final concentration of $1 \mathrm{U} / 50 \mu \mathrm{L}$ and $0.3 \mu \mathrm{M}$ NKA $\alpha 1$ forward and reverse primers. The reaction cycle sequence comprised $2 \mathrm{~min}$ at $95^{\circ} \mathrm{C}$, followed by 36 cycles comprising $45 \mathrm{~s}$ at $94^{\circ} \mathrm{C}, 45 \mathrm{~s}$ at $56^{\circ} \mathrm{C}$ and 1 min at $72^{\circ} \mathrm{C}$, with a final extension for $5 \mathrm{~min}$ at $72^{\circ} \mathrm{C}$. Samples were then rapidly cooled and held at $0^{\circ} \mathrm{C}$ before removal for storage at $-20^{\circ} \mathrm{C}$.

\section{IP-RP-HPLC of PCR Products}

The HPLC system was comprised of the binary Rainin Rabbit HPLC pumps, a MacRabbit ${ }^{\mathrm{TM}}$ system controller software, a $1.2 \mathrm{~mL}$ volume dynamic solvent mixer, column oven $\left(50^{\circ} \mathrm{C}\right)$, a
LDC-Milton Roy Spectromonitor 3000 variable wavelength UV detector set at $256 \mathrm{~nm}$ (all obtained from Rainin, Woburn, MA, USA), a pre-column filter (0.5- $\mu \mathrm{m}$ PEEK; Upchurch Scientific, Oak Harbor, WA, USA) and a Hewlett-Packard 3390A calculating integrator (Hewlett-Packard, Kennett Square, PA, USA). Solvent A was 0.1
$\mathrm{M}$ triethylammonium acetate (TEAA), $\mathrm{pH} 7.0$, and solvent $\mathrm{B}$ was $25 \%$ acetonitrile in $0.1 \mathrm{M}$ TEAA, $\mathrm{pH}$ 7.0. A gradient profile was used for elution which started with $39 \%$ solvent B, which was increased linearly to $60 \%$ solvent B over 3 min and was then followed by a linear increase to $67 \%$ solvent $\mathrm{B}$ over $4 \mathrm{~min}$. The profile was

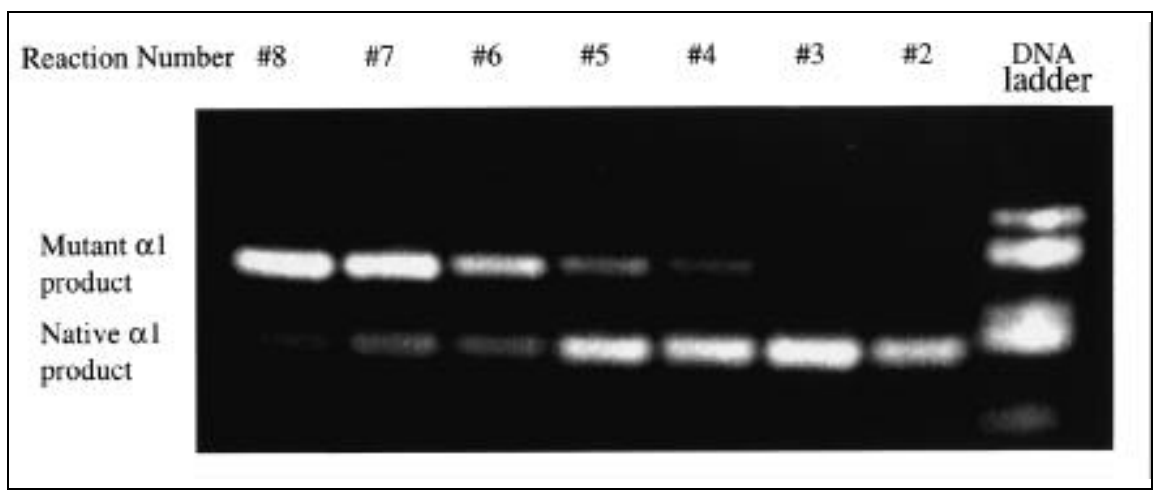

Figure 1. Products from competitive RT-PCR to quantitate sodium, potassium-ATPase $\alpha 1$ isoform gene expression in dissected kidney tissue, analyzed by agarose gel electrophoresis. From left to right, the first 7 lanes represent $15 \mu \mathrm{L}$ of products generated in sequential $50-\mu \mathrm{L}$ reactions containing equal starting amounts of native RNA and decreasing amounts of competitor mutant RNA. Amounts of mutant competitor RNA added to each reaction (\#2-\#8) were $500 \mathrm{ag}, 1 \mathrm{fg}, 5 \mathrm{fg}, 10 \mathrm{fg}, 50 \mathrm{fg}, 100 \mathrm{fg}$ and $200 \mathrm{fg}$, respectively. The native product is $245 \mathrm{bp}$ and the mutant product is $390 \mathrm{bp}$ in length. The right lane contains size markers, consisting of pUC18 DNA digested with HaeIII (visible band sizes are 587, $458 / 433,298,267 / 257$ and $174 \mathrm{bp})$.

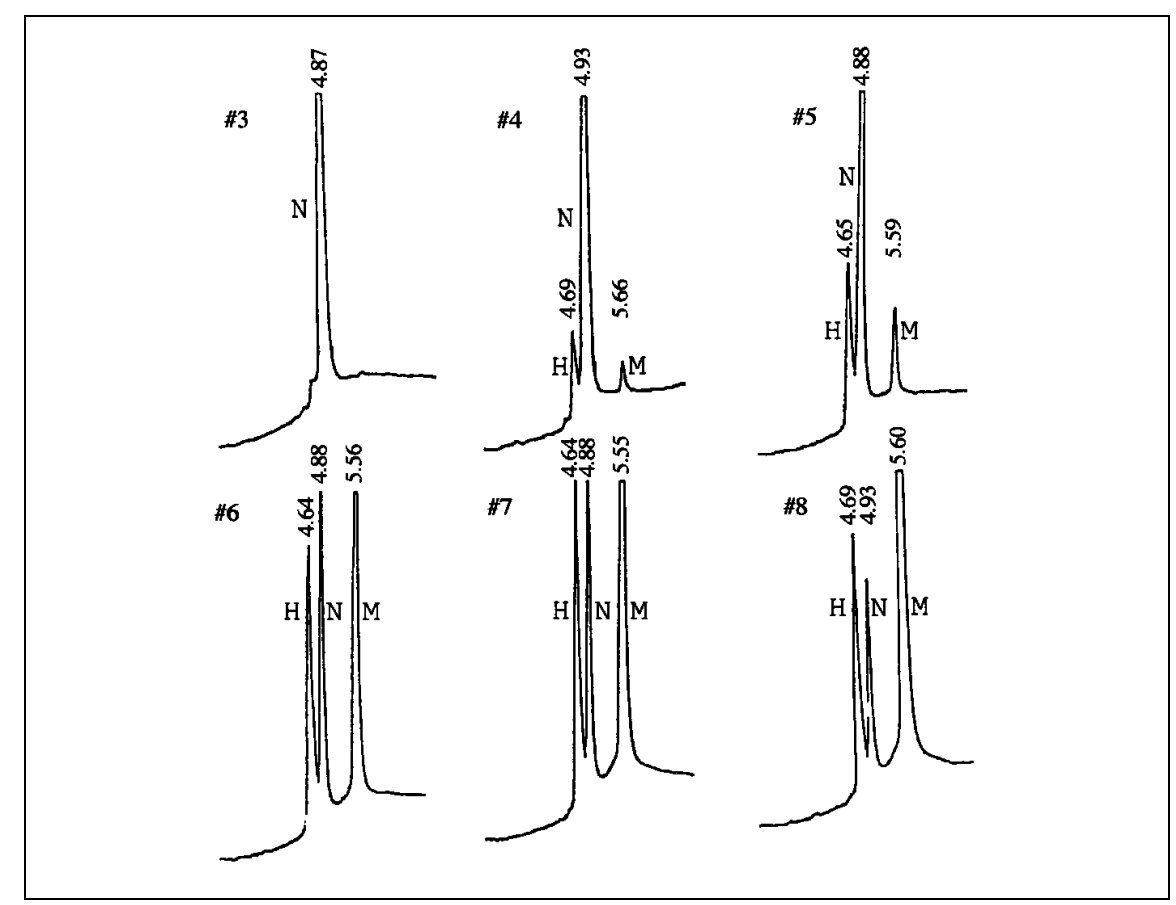

Figure 2. Products from competitive RT-PCR to quantitate sodium, potassium-ATPase $\alpha 1$ isoform gene expression in dissected kidney tissue, analyzed by IP-RP-HPLC. Chromatograms \#3-\#8 represent $10 \mu \mathrm{L}$ of products generated in sequential $50-\mu \mathrm{L}$ reactions containing equal starting amounts of native RNA and increasing amounts of competitor mutant RNA. Reactions are the same reactions analyzed by gel electrophoresis in Figure 1. Peaks represent UV absorbance at $256 \mathrm{~nm}$ of the following products: $\mathrm{N}$ denotes native product, $\mathrm{M}$ mutant product and $\mathrm{H}$ heteroduplex products, elution times are indicated. 
completed by a further linear gradient to $85 \%$ solvent $\mathrm{B}$ over $1 \mathrm{~min}, 1 \mathrm{~min}$ further at $85 \%$ solvent $\mathrm{B}$ and then a return to the starting conditions over an additional $1 \mathrm{~min}$. This gradient can be modified for products of specific known sizes to reduce elution time but retain separation of products. Flow rate was $1 \mathrm{~mL} / \mathrm{min}$.

The column used for analysis $(50 \times$ 4.6 mm i.d.; Sarasep, Santa Clara, CA, USA) was packed with nonporous

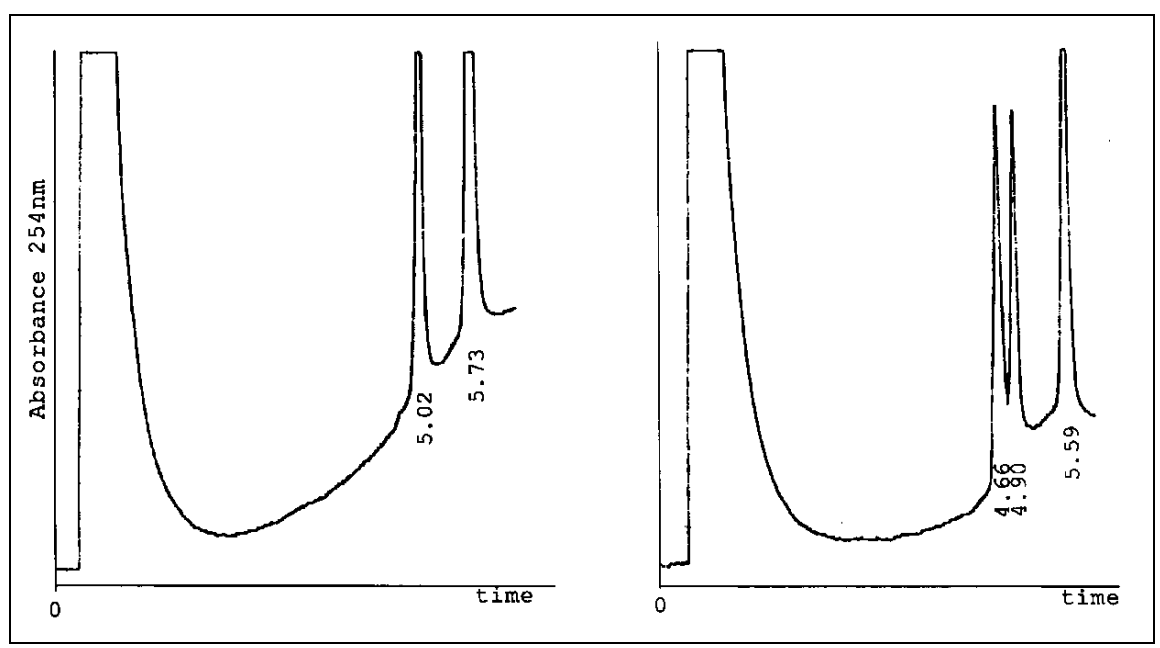

Figure 3. Chromatograms generated by IP-RP-HPLC analysis of RT-PCR products illustrating the formation of the heteroduplex products. The left-hand chromatogram was produced on IP-RPHPLC analysis of a $10-\mu \mathrm{L}$ aliquot of a mixture of products from two separate RT-PCRs, one generating only native product, the other only mutant product. The right-hand chromatogram was produced by analysis of a $10-\mu \mathrm{L}$ aliquot of the same mixture, heated to $97^{\circ} \mathrm{C}$ then cooled to $4{ }^{\circ} \mathrm{C}$, resulting in the appearance of a third peak representing the formation of heteroduplex products. Elution times of the products are marked on the chromatograms.

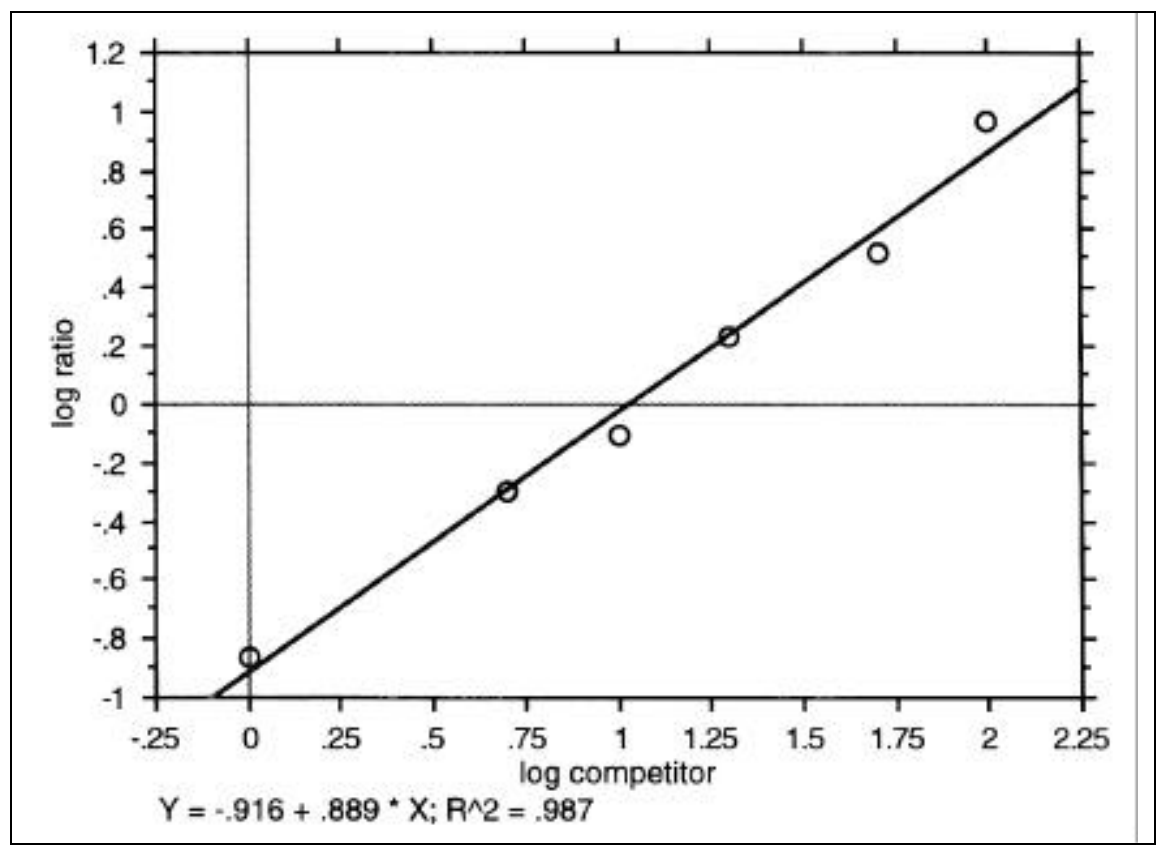

Figure 4. Regression plot generated by a representative competitive RT-PCR titration reaction to quantitate sodium, potassium-ATPase $\alpha 1$ isoform gene expression in rat blood. For each reaction tube, $\log$ ratio of native to mutant product amounts generated was plotted against the log of the corresponding initial amount of competitor RNA added. The initial amount of total blood RNA added to each reaction tube was $96 \mathrm{ng}$; the competitor input levels were 1, 5, 10,20,50 and $100 \mathrm{fg}$. The initial amount of native RNA in the blood sample was determined from the regression at the point where the log ratio= 0 . This corresponds to an expression level of $112 \mathrm{fg}$ of mutant RNA input/ $\mu \mathrm{g}$ blood total RNA. 
alkylated poly(styrene-divinylbenzene) particles prepared according to previously published protocols (2). Sample injection volume was $10 \mu \mathrm{L}$. All samples were injected without further processing.

\section{RESULTS}

Nonporous alkylated poly(styrenedivinylbenzene) packing materials are very well suited for analysis of dsDNA molecules. Rapid separation and high resolution of analytes were obtained. Further information on system optimization and size dependence of elution times is provided elsewhere (10, 11,16).

The competitive PCR products have been resolved by agarose gel electrophoresis and show the separation of increasing amounts of competitor product as the amount of competitor input is increased (Figure 1). Corresponding to the increase in competitor product, the native product is reduced. Accurate quantification of the amounts of these products is necessary when using this titration to calculate the amount of native NKA $\alpha 1$ RNA in the sample.

Figure 2 shows chromatograms obtained from PCRs whose products were previously resolved (Figure 1) by agarose electrophoresis. The chromatograms indicate a clear separation of reaction products. Increases in the ratio of competitor to native products are reflected in the chromatograms and can be readily quantified by on-line integration of the area of peaks detected in the absorbance signal ( $256 \mathrm{~nm}$ ) from a UV detector attached to the column outlet.

Competitive RT-PCR using homologous RNA standards may lead to the production of heteroduplexes formed between native and mutant products which share sequences that are partially complementary (8). Methods to separate and analyze products of these reactions must take into consideration the possibility of heteroduplex formation and account for such products in the subsequent calculations. We noted that some reactions produced an additional product peak in our chromatograms. To determine the likelihood that this product reflected heteroduplex formation, we digested reactions with $\mathrm{S} 1$ nuclease.
When the additional reaction product was present, S1 nuclease treatment resulted in its selective removal. This finding is compatible with a heteroduplex in which S1 nuclease digests the single-stranded loop formed by the unmatched competitor insert and subsequently digests the remaining nicked double-stranded product.

To confirm the identity of the third peak, native and competitor RNA were reverse-transcribed and amplified in separate reactions and then mixed together. IP-RP-HPLC analysis of this mixture revealed only two peaks (Figure 3). Heating the mixture to $97^{\circ} \mathrm{C}$ for $3 \mathrm{~min}$ and cooling to $4^{\circ} \mathrm{C}$ led to the appearance of a new product. The retention time of the third product corresponded to that of the unaccounted peak in the chromatograms of the initial set of RT-PCRs (Figure 2). There was a concomitant decrease in the peak area of the native and competitor products. Further studies indicated that the amount of the heteroduplex formed was influenced by the rate of cooling from $96^{\circ} \mathrm{C}$. Similarly, reduction in salt concentration reduced the amount of heteroduplex formed but did not prevent its formation.

The presence of heteroduplex formation is a consequence of similarity between the competitor and native products. However, such similarity is essential for the efficiency of amplification of native and competitor products to be equal. Amplification by PCR of both products using the same primers with identical efficiency is a requirement to meet the mathematical constraints of absolute quantification of gene expression (18). Quantification was performed by calculating the log of the ratio of native to competitor products in reactions that varied in the initial amount of competitor. A plot of the $\log$ ratio of products against the log of the initial amount of competitor should generate a straight line with a slope of 1. We calculated the slope and regression coefficients resulting from quantitative titrations of NKA $\alpha 1$ isoform message from RNA extracted from whole blood. Blood was chosen to examine the robustness of the system because of the low levels of expression that is limited to nucleated cells. We obtained a mean ( \pm standard error of the mean) coefficient of determination $\left(\mathrm{R}^{2}\right)$ of $0.986 \pm 0.007$ and a slope value of $0.88 \pm 0.023(n=5)$. Figure 4 shows a plot of the relationship between the ratio of reaction products and the amount of competitor added per reaction in one randomly selected titration.

We have also examined the effect of altering the amount of native RNA in-

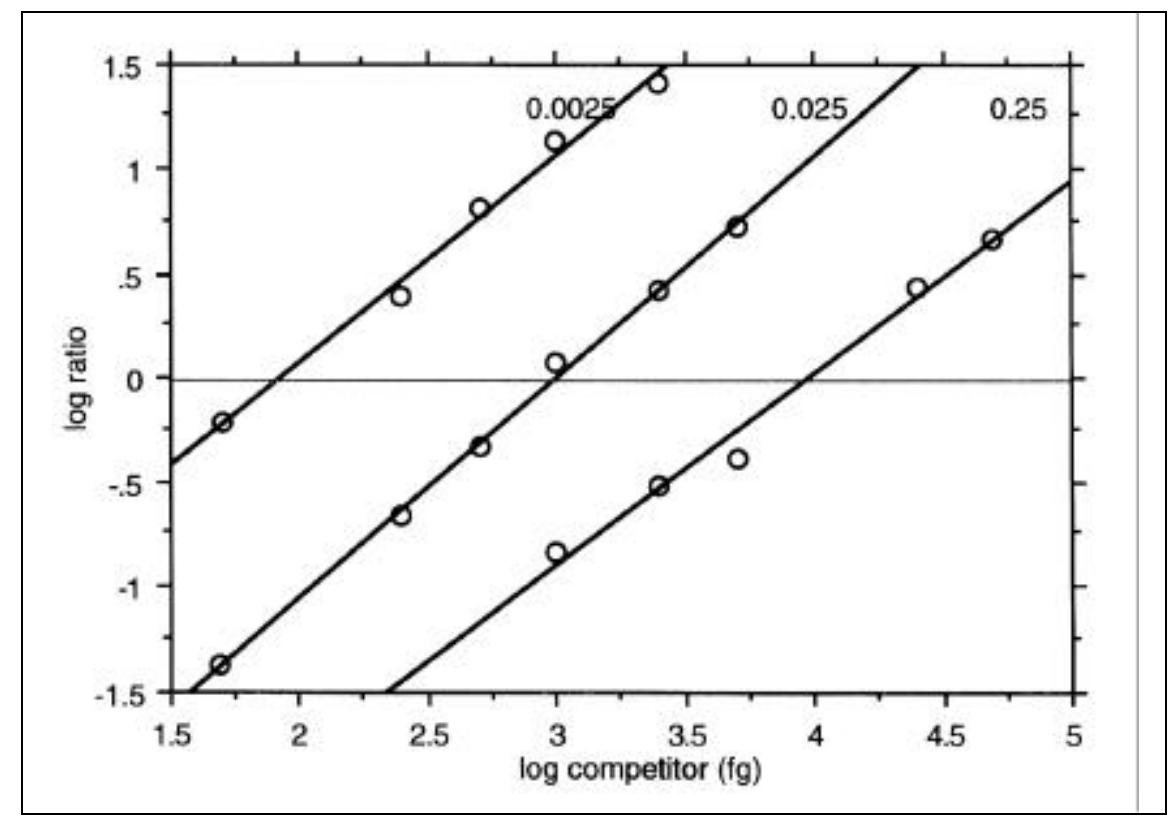

Figure 5. Regression plots from 3 RT-PCR titration reactions with different starting levels of rat brain total RNA. From left to right, plots generated by reactions initially containing $0.0025,0.025$ and $0.25 \mu \mathrm{g}$ brain total RNA are shown superimposed to illustrate their relationship. 
put on the calculated level of gene expression. This was performed using RNA from tissue with abundant NKA $\alpha 1$ expression (brain). Titrations against competitor were performed at three starting levels of native RNA obtained by diluting $1 / 10$ and $1 / 100$. Figure 5 shows the regression plots obtained at each of these input levels. The calculated amounts of gene expression determined (at each dilution) were 37.5 $\mathrm{pg} / \mu \mathrm{g}$ brain RNA $(0.25 \mu \mathrm{g}$ brain RNA/reaction), $39.2 \mathrm{pg} / \mu \mathrm{g}$ brain RNA $(0.025 \mu \mathrm{g}$ RNA) and $33.9 \mathrm{pg} / \mu \mathrm{g}$ brain RNA (0.0025 $\mu \mathrm{g}$ RNA), respectively.

\section{DISCUSSION}

Competitive titration assays for the quantification of gene expression by RT-PCR result in the generation of multiple samples because of the necessity to examine the amplification of native mRNA at several levels of com- petitor RNA input. Traditional methods for the analysis of these samples have emphasized slab gel electrophoresis that requires the preparation, loading, running and subsequent analysis of gels. This task is labor-intensive and time-consuming. Additionally, it introduces new opportunities to enter error into a quantitative system. Furthermore, to detect reaction products, DNA must be stained with potentially toxic dyes, or reaction products must be labeled or hybridized to labels so as to visualize them by fluorescence, electrochemiluminescence, autoradiography or phosphor imaging. HPLC approaches offer the possibility to avoid these time-consuming and labor-intensive activities and also to improve accuracy of quantification by reduction of sample handling. In the system reported in the present study, PCR products can be analyzed directly by IP-RP-HPLC without further sample handling. Quantification of reaction products using on-line UV absorbance detection provides accurate information concerning the amount of reaction products present in each peak. Our analyses typically employ only $10 \mu \mathrm{L}$ of a $50-\mu \mathrm{L}$ reaction volume, permitting replication of analysis. To perform these analyses with HPLC equipment is far more costeffective than fluorescence or isotopic detection and quantitation systems that are now available for gel analysis. Reduction in the overall dead volume of HPLC and optimization of the elution profile for products within a defined size range will permit the analysis of up to 30 samples per hour with little operator involvement beyond loading samples into an autosampler tray (9). This effectively minimizes an inherent limitation of HPLC, which is the necessity of sequential sample analysis.

Sensitivity of the system is illustrated by the ability to quantify expression in small volumes of whole blood in which input abundance is low (Figure 
4). We have not attempted to quantitate very low abundance inputs because as input copy number declines, the biological relevance of differences between samples is progressively reduced. The quantification of gene expression in dissected renal tissue used total RNA extracted from $0.5 \mathrm{~mm}$ of isolated nephron tissue in each reaction (Figures 2 and 3). This indicates the suitability of the method to determine quantitative expression differences using RNA from very small tissue samples.

Additional advantages emerge from the application of this system to competitive RT-PCRs that use partially homologous internal competitor RNA. Partially homologous competitors are selected for RT-PCR quantification because they can be amplified by the same primers that amplify the native gene product. However, the similarity between competitor and native sequences can result in products that have potential for heteroduplex formation (8). This occurrence has been considered a disadvantage to the accuracy of the quantitation system; however, this exists only when the analytical method fails to accurately detect and quantify heteroduplexes.

The potential for heteroduplex formation leads to a design decision whether to generate competitor RNA which differs in size from the native signal or which differs in the presence of a selected restriction site, but not in size. We have chosen to generate size variation because restriction mutants require an additional step in PCR product analysis. Furthermore, restriction enzymes are unable to digest heteroduplexes that contain recognition sequence for the restriction enzyme on only one strand. Such undigested material would not be distinguishable based on size and would therefore be mistakenly added to the balance of the undigested reaction product used to calculate the final product ratio. This problem may be reduced if heteroduplexes form with almost the same efficiency as homoduplexes in such systems. In such a system, De Kant and colleagues have shown that analysis of only the digested homoduplex product can yield reliable quantification of PCR inputs if appropriate mathematical analysis of the proportion of digestible products is performed (4). In such a system, it is also necessary to verify that restriction digestion is complete for each batch of samples.

Our experience with heteroduplex formation in the present study indicates that heteroduplexes readily formed even though our reaction products differed in size by $145 \mathrm{bp}$ and shared only $63 \%$ homology. Formation of heteroduplexes was apparent through the appearance of an additional reaction product in IP-RP-HPLC chromatograms. This product eluted with a retention time less than the 245-bp homoduplex native product. Since retention behavior is determined by the ability of dsDNA to bind the ion-pair reagent, such retention is consistent with a product containing somewhat less dsDNA than the native 245-bp product. Formation of a heteroduplex between a 390-bp competitor strand and the 245-bp native strand permits matching of a maximum of $245 \mathrm{bp}$ with a reduction in total base pairing around the location of the unmatched strand. The migration of such a heteroduplex under non-denaturing gel electrophoresis conditions is unpredictable due to the effect on mobility of the flexible single-stranded portion of the duplex and quantification of heteroduplex using dye staining of the products appears to be unreliable (20). We confirmed the identity of our heteroduplex by experiments involving melting and reannealing of a mixture of pure homoduplexes of both the native and competitor products. Heteroduplexes were more rapidly digested by $\mathrm{S} 1$ nuclease than homoduplexes, and extensive alterations in primer concentrations failed to affect heteroduplex formation (data not shown). Comparison of Figures 1 and 2 indicates that heteroduplexes are not readily identifiable when PCR products are analyzed by agarose (MetaPhor) gel electrophoresis.

The importance of analysis of heteroduplex formation to the quantitative accuracy of competitive RT-PCR cannot be overemphasized. Titrations are calculated from the ratio of reaction products. Since heteroduplexes subtract equimolarly from both homoduplex reaction products, the only circumstance when their formation will not change the ratio of homoduplex products is when the ratio is unity. By determining the amount of heteroduplex present in a reaction and reallocating each of its components back to the corresponding homoduplex, the error generated by heteroduplex formation is corrected. Thus, our experiments reveal the ease with which heteroduplexes can form even when native and competitor sequences have relatively low homology. However, they also reveal the utility of IP-RP-HPLC analysis for the detection of and correction for these products.

Raeymaekers has analyzed some of the mathematical considerations concerning competitive mutant RT-PCR (18). He has emphasized that such reactions generate log-log plots of product ratio against an initial amount of competitor which should form a straight line with a slope of unity. As demonstrated by the data obtained in Figures 4 and 5, our reactions meet linearity requirements almost ideally. Furthermore, the slopes generated by these reactions are consistently close to unity. This appears to be an important advantage of IP-RP-HPLC quantification compared with other methods that have generated slope values greatly different from unity $(8,17,19,21)$. Finally, by diluting input RNA preparations over three orders of magnitude and performing titration analysis on each of the dilutions, we have shown that the calculated initial level of gene expression is essentially unaffected by the level of initial input. The slopes of the titration lines for these reactions are indistinguishable (analysis of covariance), and the effect of dilution is to shift the titration line by the order of magnitude difference in the input RNA amount.

Ion-pair reversed-phase HPLC analysis of competitive mutant RTPCRs provides a convenient and efficient method of reaction product quantification. The IP-RP-HPLC method can also demonstrate whether heteroduplex formation has occurred and permits correct reallocation of heteroduplex components. Quantitative accuracy may benefit from the minimal amount of post-PCR product handling. Competition reactions using a competitor that is $159 \%$ greater in size results in titrations that closely approach mathematical ideals, thus indicating similar 
efficiency of amplification of native and competitor products. Dilution of input RNA over three orders of magnitude further confirms the reliability of absolute quantification by this method.

\section{ACKNOWLEDGMENTS}

This work was supported in part by Grants NIH DDK45538 (P.A.D.) and IPO1-HG00205 (P.J.O.). We are grateful to Dr. Jerry Lingrel (University of Cincinnati) and Dr. Kevin Lynch (University of Virginia) for cDNAs used in the present study.

\section{REFERENCES}

1.Becker-André, M. and K. Hahlbrock. 1989. Absolute mRNA quantification using the polymerase chain reaction (PCR). Nucleic Acids. Res. 17:9437-9446.

2.Bonn, G., C. Huber and P. Oefner, inventors. 1994. Verfahren zur trennung von nucleinsaeuren (Methods for the separation of nucleic acids). Austrian patent 398973.

3.Chang, A., J. Zhao and M. Krajden. 1994. Polymerase chain reaction kinetics when using a positive internal control target to quantitatively detect cytomegalovirus target sequences. J. Virol. Methods 48:223-236.

4.deKant, E., C.F. Rochlitz and R. Herrmann. 1994. Gene expression analysis by a competitive and differential PCR with antisense competitors. BioTechniques 17:934-942.

5.Dostal, D.E., K.N. Rothblum and K.M. Baker. 1994. An improved method for absolute quantification of mRNA using multiplex polymerase chain reaction: determination of renin and angiotensinogen mRNA levels in various tissues. Anal. Biochem. 223:239-250.

6.Ferré, F., A. Marchese, P. Pezzoli, S. Griffin, E. Buxton and V. Boyer. 1994. Quantitative PCR: an overview. In K.B. Mullis, F. Ferré and R.A. Gibbs (Eds.), The Polymerase Chain Reaction. Birkhauser, Boston.

7.Ferré, F., A.L. Marchese, S.L. Griffin, A.E. Daigle, S.P. Richieri, F.C. Jensen and D.J. Carlo. 1993. Development and validation of a polymerase chain reaction method for the precise quantitation of HIV-1 DNA in blood cells from subjects undergoing a 1-year immunotherapeutic treatment. AIDS 7 (2 Suppl): S21S27.

8.Gilliland, G., S. Perrin, K. Blanchard and H.F. Bunn. 1990. Analysis of cytokine mRNA and DNA: detection and quantitation by competitive polymerase chain reaction. Proc. Natl. Acad. Sci. USA 87:2725-2729.

9.Huber, C.G., P.J. Oefner and G.K. Bonn. 1993. Rapid analysis of biopolymers on modified nonporous polystyrene-divinylbenzene particles. Chromatographia 37:653-658.

10.Huber, C.G., P.J. Oefner and G.K. Bonn. 1995. Rapid and accurate sizing of DNA fragments on alkylated nonporous poly(styrene- divinylbenzene) particles. Anal. Chem. 67:578-585.

11.Huber, C.G., P.J. Oefner, E. Preuss and G.K. Bonn. 1993. High-resolution liquid chromatography of DNA fragments on nonporous poly(styrene-divinylbenzene) particles [published erratum appears in Nucleic Acids Res., May 11, 1993; 21:2284]. Nucleic Acids Res. 21:1061-1066.

12.Ikonen, E., T. Manninen, L. Peltonen and A.-C. Syvanen. 1994. Quantitative determination of rare mRNA species by PCR and solid-phase minisequencing. PCR Methods Appl. 1:234-240.

13.Katz, E.D. and L.A. Haff. 1990. Rapid separation, quantitation and purification of products of polymerase chain reaction by liquid chromatography. J. Chromatogr. 512:433-444.

14.Landgraf, A., B. Reckmann and A. Pingoud. 1991. Quantitative analysis of polymerase chain reaction (PCR) products using primers labeled with biotin and a fluorescent dye. Anal. Biochem. 193:231-235.

15.Noonan, K.E., C. Beck, T.A. Holzmayer, J.E. Chin, J.S. Wunder, I.L. Andrulis, A.F. Gazdar, C.L. Willman, B. Griffith, D.D. Von Hoff and I.B. Roninson. 1990. Quantitative analysis of MDR1 gene expression in human tumors by polymerase chain reaction. Proc. Natl. Acad. Sci. USA 87:7160-7164.

16.Oefner, P.J., C.G. Huber, E. PuchhammerStöckl, F. Umlauft, K. Grünewald, G.K. Bonn and C. Kunz. 1994. High-performance liquid chromatography for routine analysis of hepatitis $\mathrm{C}$ virus cDNA/PCR products. BioTechniques 16:898-908.

17.Piatak Jr., M., K.-C. Luk, B. Williams and J.D. Lifson. 1993. Quantitative competitive polymerase chain reaction for accurate quantification of HIV DNA and RNA species. BioTechniques 14:70-80.

18.Raeymaekers, L. 1993. Quantitative PCR: theoretical considerations with practical implications. Anal. Biochem. 214:582-585.

19.Schmitt, J.F., M. Guthridge, C. Economou, J. Bertolini and M.T.W. Hearn. 1992. A new quantitative polymerase chain reaction-high performance ion exchange liquid chromatographic method for the detection of fibroblast growth factor-beta gene amplification. J. Biochem. Biophys. Methods 24:119-133.

20.Schneeberger, C., P. Speiser, F. Kury and R. Zeillinger. 1995. Quantitative detection of reverse transcriptase-PCR products by means of a novel and sensitive DNA stain. PCR Methods Appl. 4:234-238.

21.Siebert, P.D. and J.W. Larrick. 1992. Competitive PCR. Nature 359:557-558.

22.Simmonds, P., P. Balfe, J.F. Peutherer, C.A. Ludlam, J.O. Bishop and A.J. Leigh Brown. 1990. Human immunodeficiency virus-infected individuals contain provirus in small numbers of peripheral mononuclear cells and at low copy numbers. J. Virol. 64:864-872.

23.Volkenandt, M., A.P. Dicker, D. Banerjee, R. Fanin, B. Schweitzer, T. Horikoshi, K. Danenberg, P. Danenberg and J.R. Bertino. 1992. Quantitation of gene copy number and mRNA using the polymerase chain reaction. Proc. Soc. Exp. Biol. Med. 200:1-6.

24.Wei, J., E.A. Walton, A. Milici and J.J.
Buccafusco. 1994. m1-m5 Muscarinic receptor distribution in rat CNS by RT-PCR and HPLC. J. Neurochem. 63:815-821.

Received 11 April 1995; accepted 4 August 1995.

\section{Address correspondence to:}

Amanda Hayward-Lester

Department of Cell Biology and Biochemistry

Texas Tech University Health Sciences Center

Lubbock, TX 79430, USA

Internet: heall@ttu.edu 